\title{
Impacts on the Urban Air Quality and Health of Global Climate Scenarios Using Different Dynamical Downscaling Approaches
}

\author{
Roberto San José1, Juan L. Pérez¹, Libia Pérez¹, Rosa M. González², Julia Pecci³, \\ Antonio Garzón ${ }^{3}$, Marino Palacios ${ }^{3}$ \\ ${ }^{1}$ Environmental Software and Modelling Group, Computer Science School, Technical University of Madrid \\ (UPM), Madrid, Spain \\ ${ }^{2}$ Department of Meteorology and Geophysics, Faculty of Physics, Complutense University of Madrid (UCM), \\ Ciudad Universitaria, Madrid, Spain \\ ${ }^{3}$ Indra S.A., C/Mar Egeo, 4, Pol. Industrial 1, Madrid, Spain \\ Email: roberto@fi.upm.es
}

Received 2 February 2016; accepted 26 April 2016; published 30 April 2016

\begin{abstract}
The objective of this publication is to present a modeling system that allows investigating the possible climate change-driven effects of air pollutants on human health. The system connects global climate change to ambient air pollution concentrations that then are linked to epidemiological endpoints. The tool has been applied to quantify the future $(2030,2050$ and 2100$)$ impact on air pollution and health of two of the IPCC global climate scenarios over the cities: Madrid, Milan and London (zone Kensington-Chelsea) with different very high spatial resolutions $(100,200$ and 10 meters) respect to the present (2011). Results indicate how ambient air pollutant concentrations respond to different climatic conditions, and how human health could be affected by changes in air pollution induced by global warning. The system includes global climate simulations, nested with regional/urban meteorological models (prognostic and diagnostic) to drive chemical transport models (offline and online modes) and a computational fluid dynamic model keeping anthropogenic emissions and the urban landscape at reference level (2011) to isolate the effects of the global climate over the city. The results of these simulations suggest that climate will have an important effect on urban air pollution and health over the next several decades, especially under the IPCC RCP 8.5 scenario.
\end{abstract}

\section{Keywords}

Climate, Dowscaling, WRF/Chem, Health

\section{Introduction}

Rapid advances in computer science and physics of the atmosphere, especially in the use of downscaling tech- 
niques offer new opportunities to investigate health problems related to urban climate [1]. Poor Air Quality (AQ) is a global issue and the evidence for adverse health effects of surface pollutants, such as ozone $\left(\mathrm{O}_{3}\right)$ and particulate matter (PM), has been strengthened in the 2013 assessment by the World Health Organization. Air pollution in both cities and rural areas was estimated to cause 3.7 million premature deaths worldwide in 2012 alone [2]. One of the most evident cases is that the surface ozone is strongly correlated with temperature during pollution episodes [3]. Uncertainty in Global Climate Model (GCM) projections of future climate change generally increases as the spatial scale of interest decreases. Dynamical downscaling of GCM fields using regional and urban climate/air quality models could significantly improve the simulation of future air quality [4]. One goal is try to understand the interaction of climate change with urban areas to provide valuable information to consider adaptation and mitigation strategies [5]. Note that to be studying urban areas need very high resolution information to capture the high spatial variability of air pollution in a city [6]. Downscaling processes and procedures offer information on climate change at an appropriate spatial and temporal scale [7].

\section{Material and Methods}

Meteorological and air quality fields corresponding to one emissions scenarios were simulated through different modelling tools for the full years of 2011 (present), 2030, 2050 and 2100 (future). We made use of a single year of simulated meteorology and air quality in this study to capture peak events that may have been moderated or lost from a statistical average over successive years. Air pollution changes were modelled for the 2030, 2050, 2100 with two climate scenarios in reference to base year (2011) conditions in the following urban areas: Madrid, Milan and London. Now we will describe the datasets and tools.

\subsection{Climate Scenarios}

The Intergovernmental Panel on Climate Change (IPCC) in the Fifth Assessment Report (AR5) has defined four possible emissions scenarios know as Representative Concentration Pathways (RCPs). The emissions scenarios RCP4.5 and RCP8.5 were selected for the global projection in this experiment as they represent medium- low and high ranges assumptions pertaining to emissions growth and radiative forcing. The RCP 8.5 [8] is developed by the MESSAGE modelling team and the IIASA Integrated Assessment Framework at the International Institute for Applies Systems Analysis (IIASA), Austria. The RCP 4.5 [9], is developed by the MiniCAM modelling team at the Pacific Northwest National Laboratory's Joint Global Change Research Institute (JGCRI). It is a stabilization scenario where total radiative forcing is stabilized around 2050 by employment of a range of technologies and strategies for reducing greenhouse gas emissions.

\subsection{Downscaling}

The downscaling system is show schematically in Figure 1. The coarse resolution $\left(1^{\circ} \times 1^{\circ}\right)$ meteorological fields of the CESM global circulation model (GCM) were dynamically downscaled to $25 \mathrm{~km}$, after which different approaches were implemented to downscale to 1 km, 200 meters and 10 meters. This process allows capture fine scale land use impacts and temperature variations. The first level (25 km of spatial resolution, Europe coverage) of the future and present year climatic conditions was simulated though the coupling of the Weather Research Forecasting (WRF/Chem) [10] mesoscale meteorological and air quality model to the global climate model CESM. WRF-Chem model represent our dynamical downscaling technique. The European air quality simulations covered all Europe with $25 \mathrm{~km}$ spatial resolution and 33 vertical levels up to $50 \mathrm{hPa}$. In the first option ( $1 \mathrm{~km}$ resolution) European results were dynamical downscaled to 5 and $1 \mathrm{~km}$ with the WRF/Chem model.

In the $1 \mathrm{~km}$ resolution Urban Canopy Model (UCM) is activated. The UCM is based on the Town Energy Budget approach by Masson [11]. In the second option (200 meters of spatial resolution) we use the diagnostic meteorological model CALMET [12] from California Air Resources Board (CARB), V5.8.4 July, $31,2013$. CALMET model is applied to process the downscaling from $25 \mathrm{~km}$ spatial resolution to $0.2 \mathrm{~km}$ spatial resolution domain centered over the cities. CALMET model can reduce the computational cost of the two dynamical downscaling levels used in the option 1. CALMET, -as a diagnostic model-, does not produce "dynamics" as WRF-Chem model so all advection and diffusion processes are neglected. In this option for the air quality data The Community Multi-scale Air Quality (CMAQ) modelling system has been also implemented [13]. The Air Quality (AQ) downscaling process over the cities is performed by running the CMAQ model over the specific 


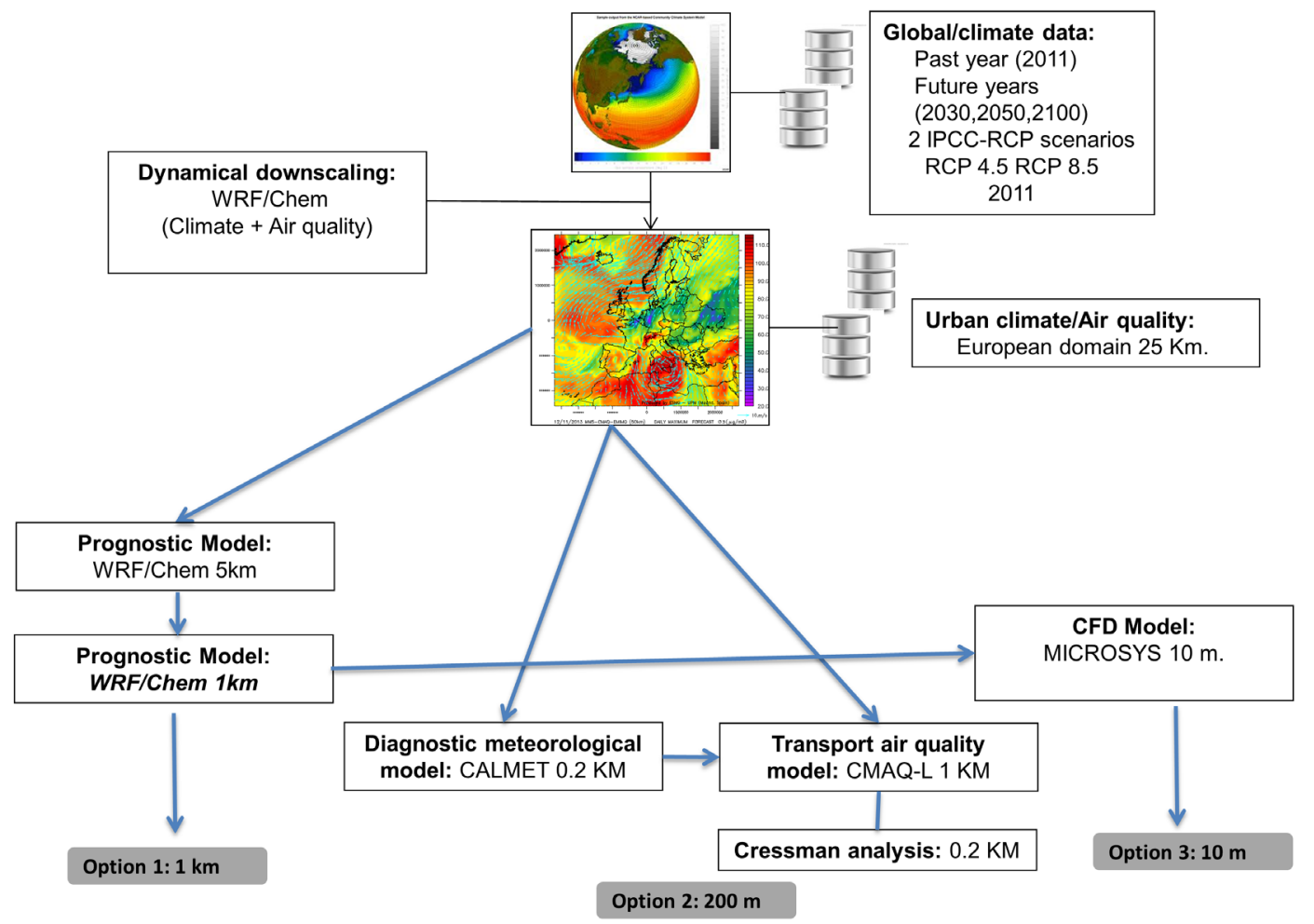

Figure 1. Flow diagram of the three downscaling approaches.

cities with $1 \mathrm{~km}$ spatial resolution, using the WRF-Chem Europe scale model outputs as boundary conditions, -a procedure also known as off-line nesting-. The GCM/CALMET linked model provides the meteorological inputs needed for the air quality simulations with CMAQ.We have used an adapted version of CMAQ for this task using "linear chemistry" which reduces on about $50 \%$ the total computational time. We will name CMAQL to the CMAQ model version with linear chemistry. The final refinement from $1 \mathrm{~km}$ to $200 \mathrm{~m}$ is developed with an interpolation tool called Cressman objective analysis [14]. Finally in the third case (the best resolution) we use a computational fluid dynamical modelling system (MICROSY) to go from the $1 \mathrm{~km}$ resolution to the 10 meters resolution over specific areas. The produced 3D fields of meteorological variables and selected pollutants in the option one $(1 \mathrm{~km})$ are used as BCs and ICs for the street scale runs over the selected urban areas. MICROSYS is based into the MIMO CFD model, which takes into account buildings obstacles. The model includes steady three-dimensional system of Reynolds equations, $\mathrm{k}-\varepsilon$ model of turbulence and the "advection-diffusion" equation to simulate pollution transport on-line coupled with a simple chemistry mechanism for $\mathrm{O}_{3}-\mathrm{NO}_{\mathrm{x}}$ relationships. The third option is the most expensive method from a computational point of view, the cheapest is the CALMET-CMAQL and intermediate approach is the WRF/Chem but with a $1 \mathrm{~km}$ spatial resolution. The level of detail of the results is correlated with the computations cost (CPU hours needed to run the simulations). In the three options, the air quality downscaling procedure requires hourly gridded emissions for the different spatial resolutions which have been generated with a emission model. The EMIMO model is an Emission Model which is capable to estimate-in a combined bottom-up and top-down approach-, the emissions of primary pollutants. EMIMO has been developed by the UPM group, for more details [15].

\subsection{Health Impact}

The methodology to estimate percentages of climate/pollution-related deaths and hospital admissions due to global climate are based on epidemiologic analysis of weather/air pollution and health data to characterize and quantify mortality/morbidity associations. The exposure-response relationships estimated from the epidemiological studies were applied to projections of climate. The short-term relationship between the daily number of deaths/hospital admissions and day-to-day fluctuations in exposure variables (temperature, heat waves, ozone 
and particles) for many cities are published indifferent scientific papers. The impacts of each climate scenario for air quality mortality/morbidity were assessed with an environmental health effects model developed by the US Environmental Protection Agency, the Environmental Benefits Mapping and Analysis Program (BenMAP) [16].

\section{Results}

Spatial differences (high resolution $200 \mathrm{~m}$.) of different health outcomes changes between (the large future) 2100 and 2011 (present) for RCP 4.5 and RCP 8.5 in the three European cities calculated from the WRF/ChemCALMET-CMAQL-MICROSYS modelling system are showed. Figure 2 shows the spatial distribution of the annual mean change (\%) in daily all causes mortality due to PM10 daily average, for 2050 following RCP 4.5 (left) and RCP 8.5 (right) scenario with $1 \mathrm{~km}$ of spatial resolution. With the RCP 8.5 climate change scenario, health problems will increase in south-east of Milan and in the west part under the RCP 4.5. For RCP 4.5 increases are located around south of the city center of Milan. In general terms, mortality change tends to decrease with RCP 4.5 and increases are detected with RCP 8.5 due to increases of the temperature and less ventilation. Figure 3 shows results for Madrid with 200 meters of resolution with the modelling system WRF/ChemCALMET-CMAQL. The gridded results have been average over districts. In Madrid the results show an increment of the hospital admissions (morbidity) following both RCP climate scenarios up to $0.04 \%$ in the 4.5 and up to $0.03 \%$ in the 8.5 . The east districts are the worst in the 4.5 and the north and south districts in the 8.5.

Steady state simulations of airflows and pollutant concentrations over London have been carried out using MICROSYS system described above with 10 meters of spatial resolution. Sample results in Figure 4 are presented.We observed strong increases in $\mathrm{NO}_{2}$ in the eastern part of the domain up to $40 \mathrm{ug} / \mathrm{m}^{3}$ under the scenario 4.5, while the 8.5 scenario decreases are expected, with no changes respect to 2011 in the central part of the domain. For London, Weak pollutant dispersion is observed in the east part of the domain under scenario 4.5 but in the scenario 8.5 the maximum values are observed in the centre part due to different wind patterns between 4.5 and 8.5.

\section{Conclusion}

A micro air pollution and health coupled simulation assessment tool was proposed and applied to study the future climate and air pollution over three European cities under two IPCC RCP possible scenarios, 4.5 and 8.5. The modeling system uses a mixed downscaling tool, dynamical-diagnostic, that produces information with different computational costs (CPU time) for different spatial resolutions (1 km, $200 \mathrm{~m}$ and $10 \mathrm{~m})$. The system includes the regional WRF/Chem model and the CALMET plus CMAQ model for the urban scale and the CFD modeling system MICROSYS. We examined the potential impacts in air quality mortality/morbidity in three large European urban areas by 2030, 2050 and 2100 using a set of global/regional/urban climate, air quality and

Differences of annual mean change mortality all causes due to PM10 (\%). Milan 1 km. 2050-2011

MILAN 200 m 2050 4.5BAU2011 - 20114.5

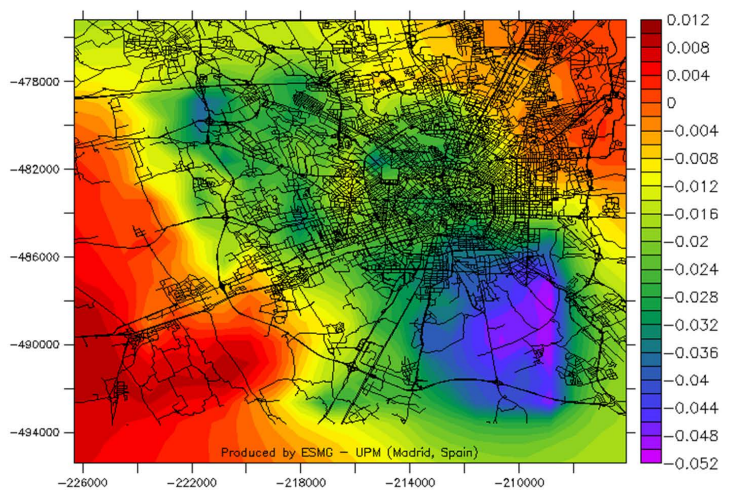

MILAN 200 m 20508.5 BAU2011 - 20118.5

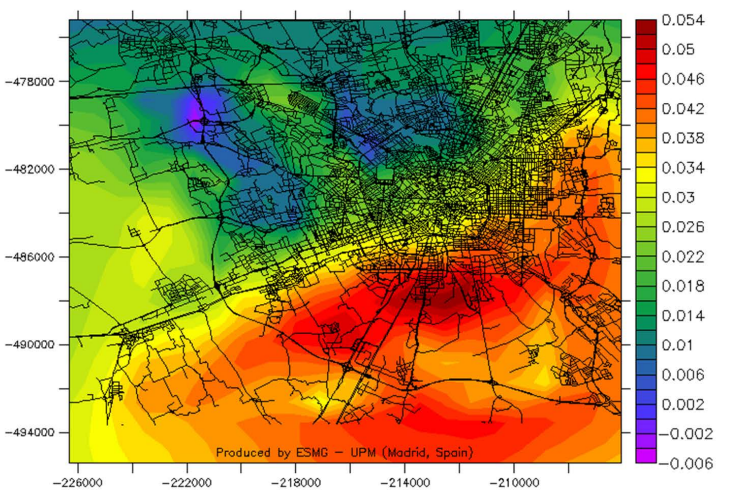

Figure 2. Spatial distribution of the differences in annual mean change (\%) mortality for 2050 respect to 2011 following RCP 4.5 (upper) and RCP 8.5 (bottom) scenarios with WRF-Chem over Milan with 1 km resolution. 
Differences of annual mean change hospital admissions respiratory causes due to 03 (\%). Madrid $200 \mathrm{~m}$. Districts
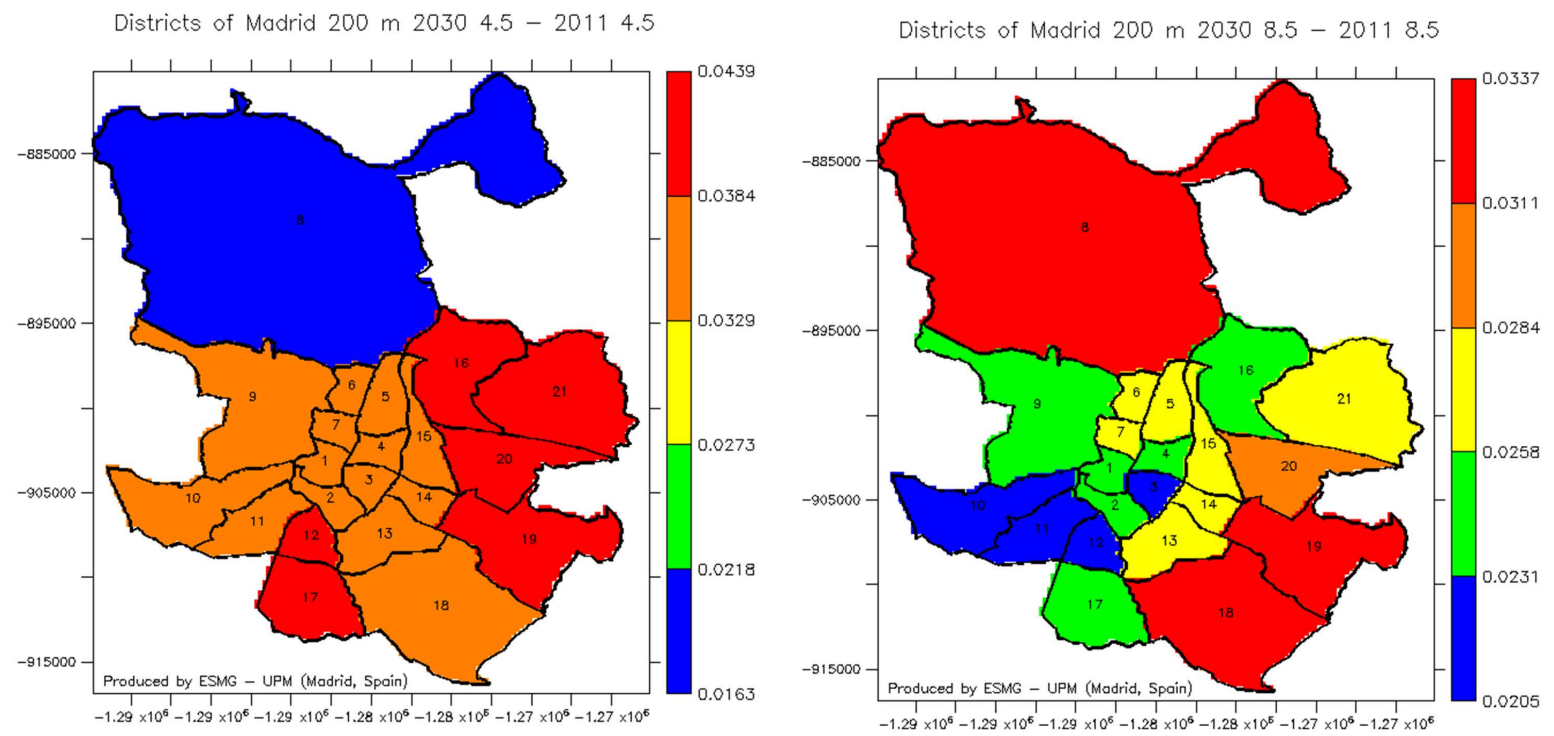

Figure 3. Madrid spatial distribution of the annual mean change (\%) in daily hospital admissions respiratory causes due to the $\mathrm{O}_{3}$ concentrations, for 2030 following RCP 4.5 (left) and RCP 8.5 (right) scenario with 200 meters of spatial resolution.

Daily average (march) NO2 concentration (NO2) and wind vectors. Buildings (white areas). London 10 meters. 2100

K\&C, London 10m. 21004.5

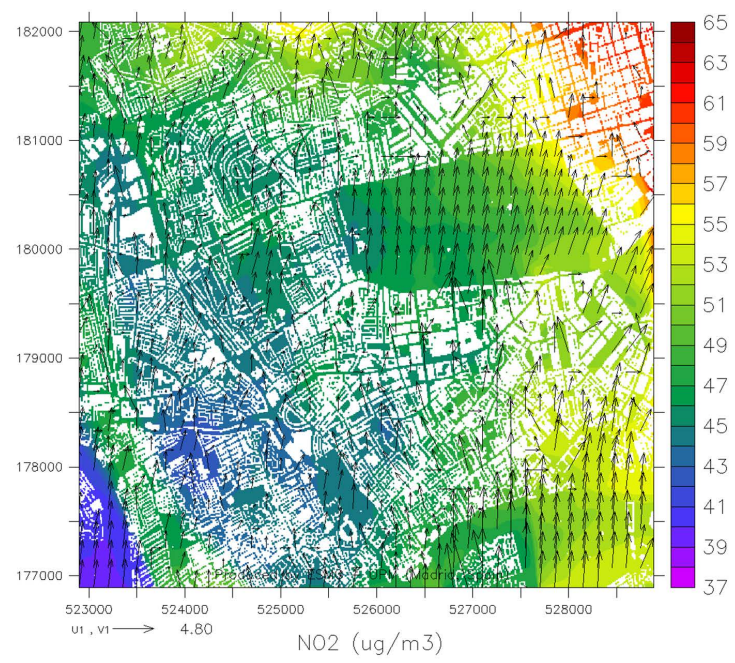

K\&C, London $10 \mathrm{~m} .21008 .5$

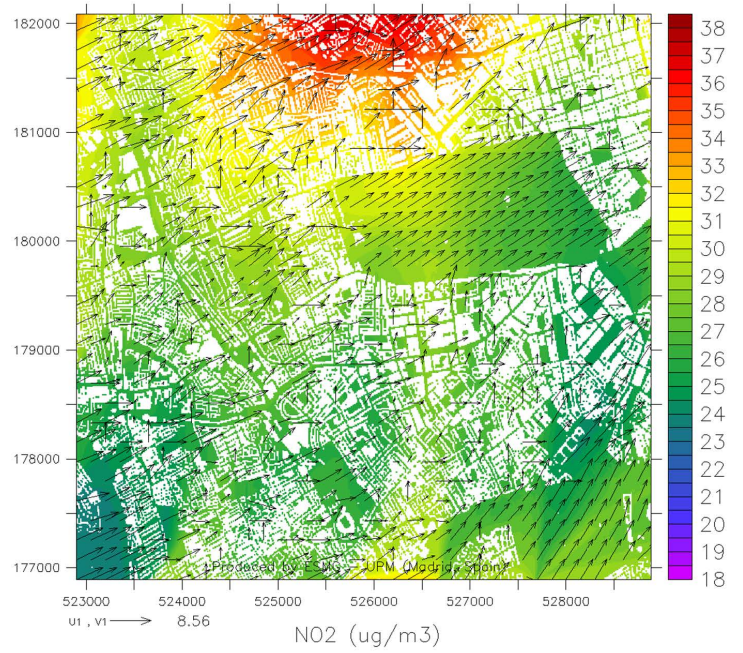

Figure 4. Differences of $\mathrm{NO}_{2}$ concentrations over London (average spring day) between 2100 and 2011 under scenario 4.5 (left) and scenario 8.5 (right).

health effects models. In this analysis, we have isolated the effect of climate change by holding local emissions and constant relative risk over time, all simulations use data from current assumptions 2011. The results of our study can support climate adaptation strategies designed to lessen the risk of air pollution concentrations exposure through mitigation of the global climate change. The most representative examples of the health impacts of future IPCC RPC climate scenarios 4.5 and 8.5 respect to 2011 are showed. The greatest impacts of the health effects of pollutants are respiratory mortality $\mathrm{O}_{3}$ (Milan and London) and cardiovascular mortality PM10 (Madrid). On 4.5 scenarios reductions occur in all variables related to temperature values but the increases are based 
on the 8.5. This scenario is characterized by temperature increase peaking impact in 2100, especially in Madrid and Milan, with large increases. Due to 4.5 scenario is characterized by decreasing temperature, this situation leads to improvements in mortality climate, especially during the 2100's in Milan. 8.5 is the opposite scenario and the results show increases in human health problems by temperature. The worst impacts are expected on Milan and Madrid, 2100. The impact on Milan is double that of Madrid and Madrid impacts are 3 times the customs for London. In the highest resolution simulations (10 meters) we have observed that the building influence is very important to detect hot spots or sensible areas to be affected by the climate change. Complex urban flows are manifest in the presence of the buildings. To improve the simulation tool, further validation studies are required by comparing simulation results with field measurements.

\section{Acknowledgements}

The UPM authors acknowledge the computer resources and technical assistance provided by the Centro de Supercomputación y Visualización de Madrid (CeSViMa). The UPM authors thankfully acknowledge the computer resources, technical expertise and assistance provided by the Red Española de Supercomputación. We acknowledge the DECUMANUS EU project from EU Space Call FP7-SPACE-2013-1 at SPA.20131.1-06. Ordnance Survey data for London: (C) Crown copyright and database rights 2015 OS 100021668.

\section{References}

[1] Rosenthal, J., Kinney, P., Knowlton, K. and Freeman, J. (2004) Assessing Potential Public Health and Air Quality Impacts of Changing Climate and Land Use in Metropolitan New York. A Study by the New York Climate and Health Project. Columbia University, New York.

[2] WHO (2013) Review of Evidence on Health Aspects of Air Pollution—REVIHAAP Project.

[3] Jacob, D.J. and Winner, D.A. (2009) Effect of Climate Change on Air Quality. Atmospheric Environment, 43, 51-63. http://dx.doi.org/10.1016/j.atmosenv.2008.09.051

[4] Gustafson, W.I. and Leung, L.R. (2007) Regional Downscaling for Air Quality Assessment: A Reasonable Proposition? Bulletin of the American Meteorological Society, 88, 1215-1227. http://dx.doi.org/10.1175/BAMS-88-8-1215

[5] Rosenzweig, C., Solecki, W., Hammer, S.A. and Mehrotra, S. (2010) Cities Lead the Way in Climate-Change Action. Nature, 467, 909-911. http://dx.doi.org/10.1038/467909a

[6] Valari, M. and Menut, L. (2008) Does an Increase in Air Quality Models’ Resolution Bring Surface Ozone Concentrations Closer to Reality? Atmos. Ocean. Tech., 25, 1955-1968. http://dx.doi.org/10.1175/2008JTECHA1123.1

[7] Giorgi, F. (2006) Regional Climate Modeling: Status and Perspectives. Journal de Physique Archives, 139, $101-118$. http://dx.doi.org/10.1051/jp4:2006139008

[8] Riahi, K., Rose, R., Runci, P., Stouffer, R., van Vuuren, D., Weyant, J., Wilbanks, T., van Ypersele, J.P., Zurek., M., et al. (2008) Towards New Scenarios for Analysis of Emissions, Climate Change, Impacts, and Response Strategies. Intergovernmental Panel on Climate Change, Geneva.

[9] Clarke, L., Edmonds, J., Jacoby, H., Pitcher, H., Reilly, J. and Richels, R. (2007) Scenarios of Greenhouse Gas Emissions and Atmospheric Concentrations. Sub-Report 2.1A of Synthesis and Assessment Product 2.1 by the U.S. Climate Change Science Program and the Subcommittee on Global Change Research. Department of Energy, Office of Biological \& Environmental Research, Washington DC, 154 p.

[10] Grell, G.A., Peckham, S.E., Schmitz, R., McKeen, S.A., Frost, G., Skamarock, W.C. and Eder, B. (2005) Fully Coupled “Online” Chemistry in the WRF Model. Atmos. Environ., 39, 6957-6976. http://dx.doi.org/10.1016/j.atmosenv.2005.04.027

[11] Masson, V. (2000) A Physically-Based Scheme for the Urban Energy Budget in Atmospheric Models. Boundary Layer Meteorol, 94, 357-397. http://dx.doi.org/10.1023/A:1002463829265

[12] Scire, J.S., Strimaitis, D.G. and Yamartino, R.J. (2000). A User's Guide for the CALMET Meteorological Model (Version 5). Earth Tech, Inc., Concord. http://www.src.com/calpuff/download/CALMET_UsersGuide.pdf

[13] Byun, Young, J., Gipson, G., Godowitch, J., Binkowsky, F., Roselle, S., Benjey, B., Pleim, J., Ching, J.K.S., Novak, J., Coats, C., Odman, T., Hanna, A., Alapaty, K., Mathur, R., McHenry, J., Shankar, U., Fine, S., Xiu, A. and Lang, C. (1998) Description of the Models-3 Community Multiscale Air Quality (CMAQ) Model. In: Proceedings of the American Meteorological Society 78th Annual Meeting, Phoenix, 11-16 January 1998, 264-268.

[14] Cressman, G.P. (1959) An Operational Objective Analysis System. Mon. Weather Rev, 87, 367-374. http://dx.doi.org/10.1175/1520-0493(1959)087<0367:AOOAS>2.0.CO;2 
[15] San, J.R., Perez, J.L., Morant, J.L. an Gonzalez, R.M. (2008) European Operational Air Quality Forecasting System by Using MM5-CMAQ-EMIMO Tool. Simulation Modelling Practice and Theory, 16, 1534-1540. http://dx.doi.org/10.1016/j.simpat.2007.11.021

[16] U.S. EPA (U.S. Environmental Protection Agency) (2010) BenMap: Environmental Benefits Mapping and Analysis Program User's Manual, Appendix. U.S. EPA, Office of Air Quality Planning and Standards, Research Triangle Park. 